\title{
DEVELOPMENT OF AN INTELLIGENT YIELD MONITOR FOR GRAIN COMBINE HARVESTER
}

\author{
Minzan Li, Peng Li, Qi Wang, Jianqing Fang, Maohua Wang \\ Key laboratory of Modern Precision Agriculture System Integration Research, Ministry of \\ Education, China Agriculture University, Beijing 100083,China.limz@cau.edu.cn
}

Abstract: An intelligent yield monitor for grain combine harvester was developed. The harvested crop was wheat, and the harvesting combine used to equip the monitor was JL1065, a typical machine with 4-meter swath width in northern China. The monitor can collect four analog signals, grain flow, grain moisture content, grain temperature, and header up/down signal, and two digital signals, ground speed and elevator speed. Two digital signals were sensed by Hall effect elements. The monitor can also synchronously receive DGPS signal. A liquid crystal display and a touch screen were integrated as an $\mathrm{I} / \mathrm{O}$ interface. Field tests showed a linear relationship between actual yield and the output of the yield monitor. The error between measurement and prediction was less than $3 \%$. It is concluded that the developed intelligent yield monitor is practical.

Key words: artificial intelligence, yield monitor, yield mapping, precision agriculture

\section{INTRODUCTION}

Yield monitor is an important component of precision agriculture ${ }^{(1,2)}$. Yield maps provide feedback for determining the effects of management inputs such as fertilizer and lime, seed and pesticides, and cultural practices such as tillage, irrigation and drainage ${ }^{(3,4)}$. Some commercial yield monitors are available, such as Greenstar ${ }^{\circledR}$, Fieldstar $\left(\right.$, Ag Leader $\left({ }^{\circledR}\right.$ and AFS $\left({ }^{(5,6)}\right.$. However, all these systems were designed for large combine harvester used by American or European farmers. It is difficult to apply this type of monitors to typical small Chinese machine. In addition, their high price is 
another obstacle for their application in developing countries like China. Thus it is necessary to develop an intelligent yield monitor for grain combine harvester in China ${ }^{(7)}$.

This paper describes a new impact type of grain yield monitor used for small combine harvester with the swath width less than 4 meters, and reports the results of performance test and field test, and finally gives an evaluation of its practicability.

\section{DEVELOPMENT}

In order to obtain correct grain yield information and yield map, except for grain weight sensor or grain bulk sensor, some other sensors are necessary. Figure 1 shows the yield monitor system developed. It includes six sensors (grain flow sensor, header height sensor, elevator speed sensor, ground speed sensor, grain moisture and temperature sensor) and some other components, such as a GPS receiver, a liquid crystal display (LCD), a touch screen, and an intelligent controller.

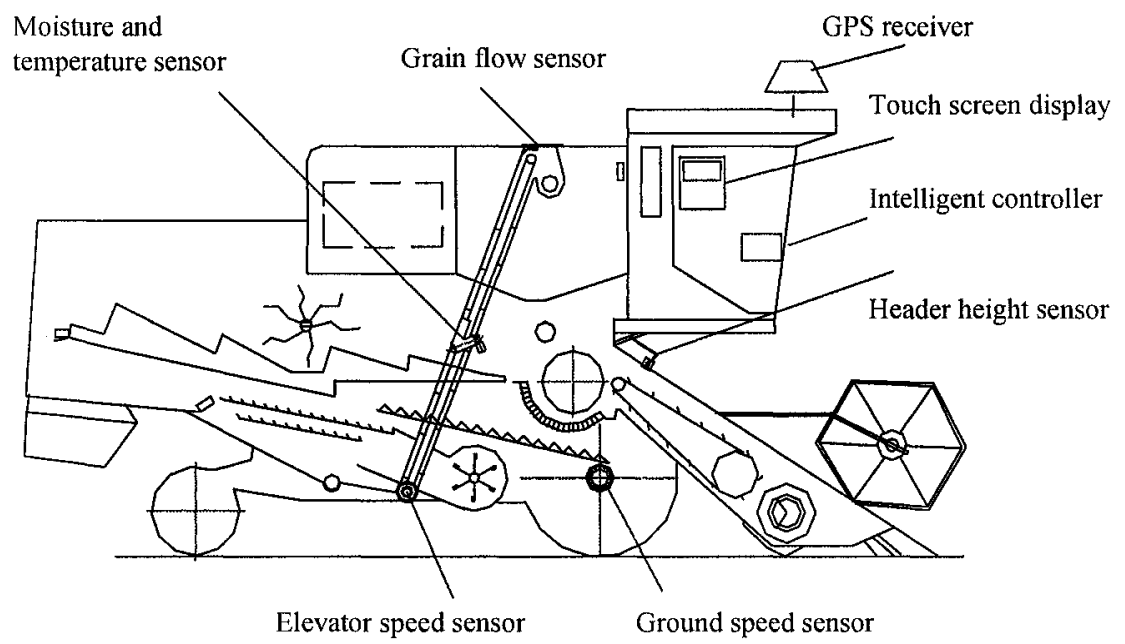

Figure 1. Components of the grain yield monitoring system developed

The yield monitor collected four analog signals (grain flow, header height, grain moisture, and grain temperature), two pulse signals (ground speed and elevator speed), and DGPS data at the same time. After a series of process, the system stored all data on a CompactFlash $\mathbb{B}(\mathrm{CF})$ card once per second. The yield monitor also included a liquid crystal display (LCD) and a touch screen as the Man-Machine interface ${ }^{(8)}$. 
Figure 2 shows the diagram of the yield monitor developed. It used a P80C592 manufactured by Philips Semiconductors as the microcontroller. It had a 10-bit analog-to-digital converter (ADC) with 8 multiplexed analog inputs and 15 interrupt sources with 2 priority levels ${ }^{(9)}$.

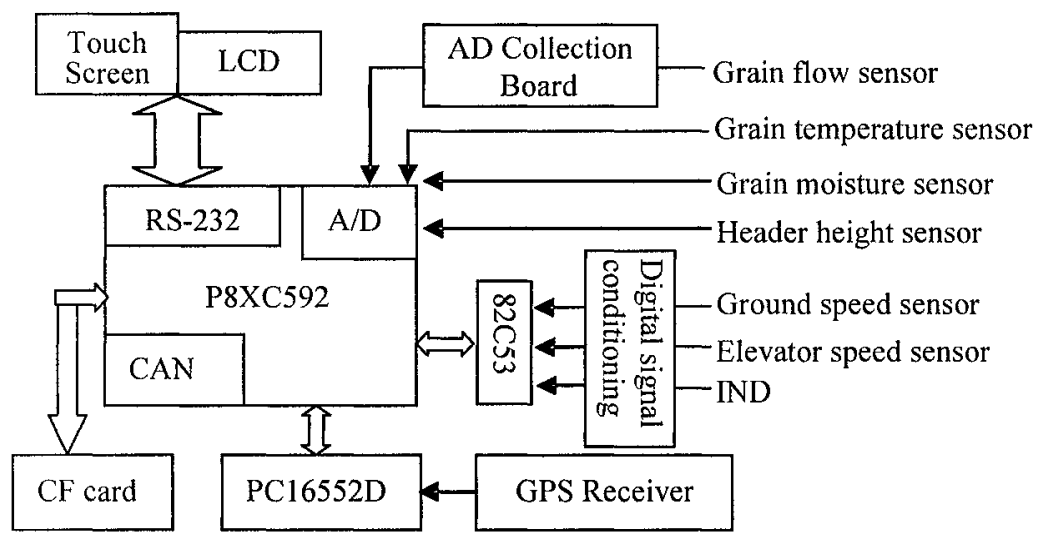

Figure 2. Diagram of the yield monitor system developed

For each analog signal, the microcontroller used an analog channel to collect it. Then these signals were converted into digital. Two Hall effect sensors were individually mounted in the drive shaft of the front wheel and the shaft of elevator to measure ground speed and elevator speed respectively. Each of them was able to generate a square wave with a frequency in direct proportion to the measured speed. Data storage device was a necessary part of the system. Storage media should be large enough and safe enough to save all the data mentioned above once per second for several days or even a whole harvest season. CompactFlash ${ }^{\circledR}$ card was chosen as the storage media. The user interface consisted of a touch screen and a LCD. The touch screen was used to input some parameters and settings for system configuration. The LCD was used to show the data related to yield. Microcontroller operated these two devices through RS-232 serial port. 


\section{TESTING AND MODELING}

\subsection{Lab Test and Modeling}

Grain flow sensor is the most important part of yield monitor system. It was performance-tested on a special test-bed in laboratory. The test-bed was made by a elevator of combine harvester, a driving motor and a adjustor to change RPM of the motor, a hopper to input grain to the elevator, and a chamber. The grain flow sensor was fixed in the chamber near the outlet of the elevator so that it can monitor the grain flow and then change the grain impact to an electric signal.

Firstly, the sensitivity of the grain flow sensor was tested. Figure 3 shows an example of the test result. It is obvious that when grain was input to the test-bed the output signal of the sensor jumped remarkably and kept stable in high level. A linear estimation model was proposed to transform the output of the flow sensor to grain weigh (wet):

$$
W=k U
$$

where, $U$ was the output of flow sensor (V); $k$ was a coefficient obtained from sensitivity test (calibration) as shown in Figure $3 ; W$ was the grain weight. The frequency of sampling and transforming was $1 \mathrm{~Hz}$, so that $W$ also meant the grain flow. Table 1 shows the test result.

Table 1. Result of repeatability test for grain flow sensor

\begin{tabular}{|c|c|c|c|}
\hline Number & $\begin{array}{c}\text { Estimated Weight } \\
(\mathrm{kg})\end{array}$ & $\begin{array}{c}\text { Scale Weight } \\
(\mathrm{kg})\end{array}$ & Error \\
\hline 1 & 277.1 & 277 & $0.04 \%$ \\
\hline 2 & 328 & 324.3 & $1.14 \%$ \\
\hline 3 & 311 & 341.1 & $8.82 \%$ \\
\hline 4 & 309 & 318.4 & $2.95 \%$ \\
\hline 5 & 311 & 315.7 & $1.49 \%$ \\
\hline Sum & 1536.1 & 1576.5 & $2.56 \%$ \\
\hline
\end{tabular}




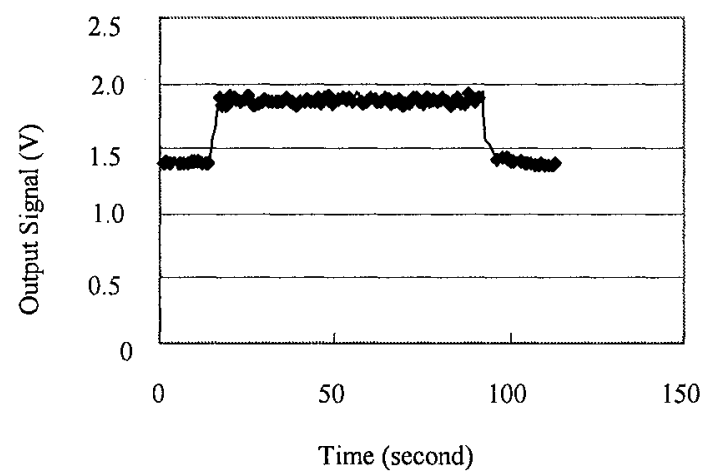

Figure 3. Result of sensitivity test for grain flow sensor

Five tests were executed and the estimation errors were calculated based on equation (2):

Error $=($ Estimated Weight - Scale Weight $) /($ Scale Weight $) \times 100 \%(2)$ Except for test 4, all other errors were smaller than 3\%. If calculated the sum of grain weight for all five tests, the relative error between estimated weight and scaled weight was $2.56 \%$. All these showed that the repeatability of the flow sensor was practical.

\subsection{Field Test}

\subsubsection{Calibration method}

In field test, the flow sensor was calibrated again to correct the coefficient $k$ obtained from equation (1). The calibration steps were listed below:

(1) Harvesting a piece of field, then calculating the grain weight (wet) with equation (1). The coefficient $k$ was initially set as the system default value $(0.9)$ obtained from lab test.

(2) Measuring the actual weight of the harvested grain (wet).

(3) Inputting the actual weight to the system through touch screen.

(4) System automatically calculated the new $k$ according to equation (3):

$$
k=k_{1} \times W_{1} / W_{2}
$$

where $W_{1}$ was the actual weight of the harvested grain; $W_{2}$ was the weight calculated by system; $k_{1}$ was the value of the coefficient $k$, which was just used in the harvest. The calibration can be repeated several times to improve sensor accuracy. 


\subsubsection{Calibration in field}

First field test with total six loads was performed on June 11, 2004. The data of the six loads are shown in Table 2. Calibrations were conducted in the first three loads, and then validation was executed in the last three loads. System used the default value of $k(0.9)$ for the first calibration. The huge error of $45.55 \%$ showed that the default value obtained from the simulation test was not fit for real harvests. Calibration changed the value of $k$ to 0.618 , and the errors in the second and third loads were greatly decreased. After the third calibration, the value of $k$ was modified to 0.613 ; and then it was not changed in last three loads (validation test). The errors of the last three loads were all less than $3 \%$. Therefore, the flow sensor performed well in linearity and stability.

Table 2 Data and result of the field test on June 11, 2004

\begin{tabular}{|c|c|c|c|c|}
\hline $\begin{array}{c}\text { Load } \\
\text { number }\end{array}$ & Value of $k$ & $\begin{array}{l}\text { Actual grain } \\
\text { weight (wet) } \\
\quad(\mathrm{kg})\end{array}$ & $\begin{array}{c}\text { Grain weight (wet) } \\
\text { measured by system } \\
(\mathrm{kg})\end{array}$ & Error \\
\hline 1 & 0.900 & 366.2 & 533 & $45.55 \%$ \\
\hline 2 & 0.618 & 277.1 & 277 & $-0.04 \%$ \\
\hline 3 & 0.618 & 383.1 & 380 & $-0.81 \%$ \\
\hline 4 & 0.613 & 421.7 & 426 & $1.02 \%$ \\
\hline 5 & 0.613 & 406.6 & 416 & $2.31 \%$ \\
\hline 6 & 0.613 & 375.4 & 381 & $1.49 \%$ \\
\hline
\end{tabular}

Second field test was taken on June 13, 2004. The data are shown in Table 3. The $k$ value of 0.613 from the last test was used for calibration in the first load. After the calibration, the errors of the second and third loads decreased significantly. However, the error in the first load of the test was much bigger than the errors in the second and third loads of the previous test. The possible reason was thought to be environmental temperature. The environmental temperature increased greatly between the two days, and the grain moisture decreased greatly. So the ground speed and grain flow would both increase in the second test. The several changed conditions contributed to the increase in error.

The difference between the two tests shows that the system calibration method should be improved, so that the system can work with a high accuracy for a relatively long period of time. 
Table 3 Data and result of the field test on June 13,2004

\begin{tabular}{c|c|c|c|c}
\hline $\begin{array}{c}\text { Load } \\
\text { number }\end{array}$ & Value of $k$ & $\begin{array}{c}\text { Actual grain } \\
\text { weight (wet) } \\
(\mathrm{kg})\end{array}$ & $\begin{array}{c}\text { Grain weight (wet) } \\
\text { measured by developed } \\
\text { system (kg) }\end{array}$ & Error \\
\hline 1 & 0.613 & 418.4 & 367 & $-12.28 \%$ \\
\hline 2 & 0.705 & 324.3 & 328 & $1.14 \%$ \\
\hline 3 & 0.705 & 362.5 & 367 & $1.24 \%$ \\
\hline
\end{tabular}

\section{SUMMARY}

An intelligent yield monitor for grain harvester based on an 8-bit microcontroller was developed. A long time of laboratory and field tests showed that the monitor was in high accuracy and practicability.

Modeling of the grain flow sensor in both laboratory and field tests showed that the sensor had a high linearity and worked steadily. Field test showed that the system had the capability to predict accumulated grain mass with an error less than $3 \%$ under the given harvest conditions. More filed tests are needed to improve the calibration method and to reduce the effect of the harvest conditions on measurement accuracy of the monitor system.

\section{ACKNOWLEDGEMENTS}

This study was supported by National High Technology Research and Development Program of China (863 Program): Research and Demonstration for Digital Agriculture (2003AA209040).

\section{REFERENCES}

[1] Blackmore, S, Moore, M, 1999. Remedial correction of yield map data, Precision Agriculture, 1, 53-66.

[2] Blackmore, S, 2000. The interpretation of trends from multiple yield maps. Computers and Electronics in Agriculture, 26, 37-51.

[3] Dobermann, A, et al, 2003. Processing of yield map data for delineating yield zones, Precision Agriculture, Wageningen Academic Publishers, Wageningen, 177-185

[4] MU Extension. 1998. Precision Agriculture: Yield Monitors: University of Missouri Extension. Available at: http://muextension.missouri.edu/. Accessed 29 July 2004. 
[5] GreenStar, 1997. Combine yield mapping system, Operator's Manual, Deere and Company, Moline, Illinois.

[6] Shearer, S, 1999. Elements of precision agriculture: basics of yield monitor installation and operation, Cooperative Extension Service, University of Kentucky, Lexington.

[7] Wang M, 2003. Practical practise of precision agriculture and priorities to promote technological innovation in P. R. China, Precision Agriculture, Wageningen Academic Publishers, Wageningen, 705-709.

[8] Zhang, W. G., P. Li, and Q. Wang. 2003. Design and Development of yield monitor. Progress of Information Technology in Agriculture, China Agriculture Press, Beijing, 332334.

[9] Philips Semiconductors. 1996. Product specification: P8xC592 8-bit microcontroller with on-chip CAN. 